\title{
Analysis of Rectangular Plates on Resting Winkler and Two-Parameter Elastic Foundation Models by Finite Difference Method
}

\author{
Trong Ha Nguyen \\ Department of Civil Engineering, \\ Vinh University, \\ Vinh City, Vietnam \\ trongha@vinhuni.edu.vn
}

\begin{abstract}
Analysis of rectangular plates on a rising elastic foundation is common when designing the foundation of civil, traffic, and irrigation works. The current research presents the results of the analysis of rectangular plates on rising Winkler elastic and two-parameter foundation using the finite difference method. The computational programming was done on Matlab. The results of the research verify the accuracy of the FEM and are in agreement with findings in the literature. In addition, this research also compares the calculation results of two foundation models and investigates the change of plate height ratio to plate size.
\end{abstract}

Keywords-finite difference method; Kirchhoff's plate; Winkler foundations; two-parameter elastic foundation

\section{INTRODUCTION}

A plate on a rising elastic foundation is a common type of structure when designing the foundation of civil works. Analysis of this problem is related to the solution of the differential equations that describe it. Finding a simple calculation method that still yields accurate results is the topic of this research. The combination of Kirchhoff's classic plate theory with Finite Difference Method (FDM) has been the topic of many studies. Authors in [1] proposed the application of FDM to study of the phenomenon in the theory of thin plates. Authors in [2] analyzed rectangular thin plates by using FDM. In [3] FDM was proposed to analyze a rectangular steel plate. The plate was considered to be subjected to an arbitrary transverse uniformly distributed loading and was considered to be clamped on two opposite edges and free at the other two edges. Authors in [4] presented an investigation of the validity of FDM on simulations of a thin sectorial steel plate under the effect of uniform and concentrated loads with different types of boundary conditions. Authors in [5] analyzed the rectangular Kirchhoff plate on Winkler foundation using Finite Fourier sine transform. The plate was assumed homogeneous, isotropic, and simply supported at the four edges. Analysis of plate on a rising elastic foundation is an also interesting topic. Authors in [6] proposed simple computer analysis of circular rafts under varying axisymmetric loading and elastic foundation conditions and authors in [7] analyzed the circular tank foundations with
FDM. In [8], authors used finite element approach to study elastic soil-structure interaction. Finite and infinite dynamic plate-soil interaction, flexible and rigid plates on homogeneous, layered or Winkler soil were studied in [9]. Finite/infinite element analysis of a thick plate on a layered foundation was proposed in [10]. One can conclude that the research on the analysis of rectangular plates on resting Winkler and twoparameter elastic foundation models by using FDM is still limited. Therefore, this study aims at analyzing rectangular plates on resting Winkler and two-parameter elastic foundation models by FDM. The Matlab program combines the Kirchhoff's classic plate theory, Winkler foundation model, two-parameter foundation model, and FDM. In addition, this research also compares the calculation results of the two foundation models and investigates the change of plate height ratio to plate size.

\section{THEORETICAL FRAMEWORK}

\section{A. Finite Diffrence Method}

FDM is a popular numerical method due to its straightforward approach and minimum requirements regarding computer resources. It is based on a mathematical discretization of the equations of boundary problems. The contents of the method are to replace the derivative by a finite estimation. This method is sufficiently accurate for thin plate analysis $[11,12]$.

\section{B. Elastic Foundation Models}

The elastic foundation is modeled by a one-, two- or manydimensional elastic spring. Several mathematical descriptions of the elastic foundation are proposed in $[12,13]$. In this research, the Winkler model and the two-parameter elastic foundation will be presented and used.

\section{1) Winkler Foundation Model}

Winkler foundation model was proposed in [14]. It is based on the assumption that the foundation's reaction $q(x, y)$ at any point $(x, y)$ on the plate is directly proportional to the displacement $w(x, y)$ at the point, and the proportionality constant $k$, called Winkler modulus, is a constant for the entire 
foundation (or the foundation modulus) as shown in (1):

$$
q(x, y)=k w(x, y)
$$

\section{2) Two-Parameter Elastic Foundation Model}

Two-parameter elastic foundation model was proposed in $[5,15]$. The foundation reaction is shown in the following expression:

$$
q(x, y)=k w(x, y)-T \nabla^{2} w(x, y)
$$

where $k$ and $T$ are the foundation model parameters.

Equation (2) can be rewritten for rectangular or circular foundations:

$$
q(x, y)=k w(x, y)-T \frac{d^{2} w(x, y)}{d x^{2}}
$$
[5]:

Equation (2) can be rewritten for the Hetenyi foundation as

$$
q(x, y)=k w(x, y)-D \nabla^{4} w(x, y)
$$

where $D=\frac{E_{p} h_{p}^{3}}{12\left(1-\mu_{p}^{2}\right)}$ is the flexural rigidity of the elastic plate and $k$ is Winkler modulus. $k$ and $D$ are the model parameters. $E_{p}$ and $\mu_{p}$ are the Young's modulus and Poisson's ratio of the plate material, and $h_{p}$ is the plate thickness.

Equation (2) can be rewritten for the Pasternak foundation as [15]:

$$
q(x, y)=k w(x, y)-G \nabla^{2} w(x, y)
$$

where, $G$ is the shear modulus of the shear layer. $k$ and $D$ are the Pasternak foundation model parameters.

Equation (2) can be rewritten in two-parameter Pasternak foundation form as:

$$
q(x, y)=k w(x, y)-k_{s} \nabla^{2} w(x, y)
$$

where $k$ is the first elastic foundation parameter (Winkler modulus) and $k_{s}$ is the second elastic foundation parameter.

\section{Classical Thin Plate Theory (Kirchhoff)}

Analysis of a thin plate subjected to loads acting normal to its surface requires solution of differential equations of threedimensional elasticity. Authors in [17] proposed the exact bending analysis for thin plates. However, this method is somewhat complex and time-consuming. To overcome the above disadvantages in technical applications, Kirchhoff's classical theory of thin plates yields sufficiently accurate results without the need of carrying out full three-dimensional stress analysis. The governing differential equation for deflection of thin plates by Kirchhoff's theory is [18]:

$$
\nabla^{4} w(x, y)=\frac{p_{z}(x, y)}{D}
$$

where $w$ denotes the deflection in $z$ direction due to the load $p_{z}$ on surface $x-y . D$ is the flexural rigidity of the elastic plate expressed as: $D=\frac{E h^{3}}{12\left(1-\mu^{2}\right)}$. In this expression: $E$ is the modulus of elasticity of the plate material, $h$ is the thickness of plates, $\mu$ is Poisson's ratio for the plate material. Equation (7) is solvable by using FDM.

\section{MethodOLOGY}

\section{A. Rectangular Kirchhoff plate on Winkler Foundation Model}

Consider a rectangular plate $a \times b$ resting on a Winkler foundation model as shown in Figure 1. The governing equation is:

$$
\nabla^{4} w(x, y)+\frac{k}{D} w(x, y)=\frac{p_{z}(x, y)}{D}
$$

For $0 \leq x \leq a, 0 \leq y \leq b$, where $k$ is the Winkler modulus, $w(x, y)$ is the deflection of the plate middle surface, $q(x, y)$ is the external distributed load applied to the plate, $a$ and $b$ are the length and width of the plates.

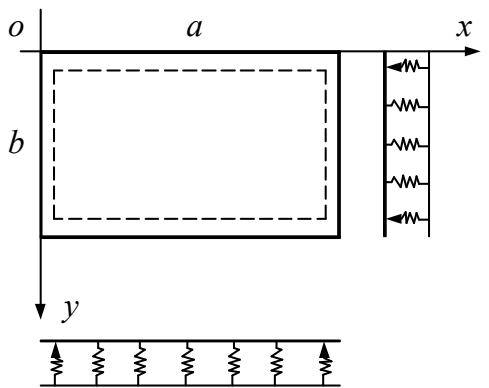

Fig. 1. Rectangular plate resting on a Winkler foundation

\section{B. Rectangular Kirchhoff Plate on Two-Parameter} Foundation Model

Consider a rectangular plate $a \times b$ resting on a twoparameter foundation (Pasternak foundation) as shown in Figure 2.

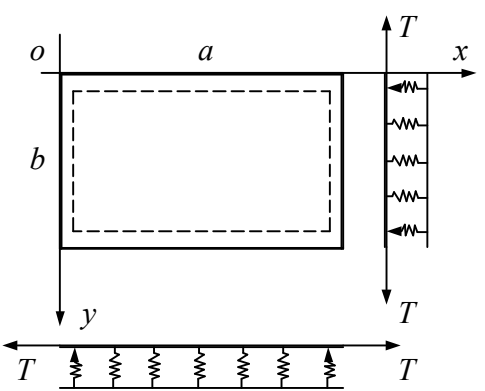

Fig. 2. Rectangular plate resting on two-parameter (Pasternak foundation)

The governing equation can be expressed by:

$$
\nabla^{4} w(x, y)+k_{s} \nabla^{2} w(x, y)+k w(x, y)=\frac{p_{z}(x, y)}{D}
$$

For $0 \leq x \leq a, 0 \leq y \leq b$, where $k$ is the Winkler 
modulus, $w(x, y)$ is the deflection of the plate middle surface, $p_{z}(x, y)$ is the external distributed load applied to the plate, and $a$ and $b$ are the length and width of the plate.

\section{Flowchart}

The steps taken on the analysis of a rectangular Kirchhoff plate on an elastic foundation are:

- Assume displacement and make finite difference grid.

- Replace the corresponding partial differential equations (8)(9) of the problem at the same transform with the finite difference equation or difference equation.

- Establish algebraic equations with the displacements as variables

- Solve the system of equations to determine the displacement.

- Determine stress and deformation from displacement by differential method.

Figure 3 shows the respective flowchart.

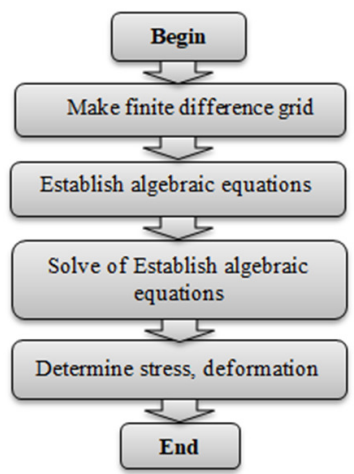

Fig. 3. Flowchart of the analysis of rectangular Kirchhoff' plates on an elastic foundation

\section{NUMERICAL RESULTS}

\section{A. Validation of Sample Plates on Matlab}

The flowchart of the program is shown in Figure 3. In order to validate this program, square plates of $a / b=1$ and plate thickness $h=1 / 100(\mathrm{~cm})$ were considered. Differential mesh division in two cases $\Delta_{x}=\Delta_{y}=a / 4(\mathrm{~cm})$ and $\Delta_{x}=\Delta_{y}=a / 8(\mathrm{~cm})$ was considered. Uniformly distributed load was $p=-100 \mathrm{kN} / \mathrm{m}^{2}$ and Young' modulus was $E=2.1 \times 10^{5} \mathrm{MPa}$, while Poisson's ratio of the plate material was $\mu=0.3$. Non-dimensional deflections and stresses, defined in [18] are:

$$
\begin{aligned}
& \bar{w}=w(0,0)\left(\frac{E h^{3}}{a^{4} p}\right), \bar{\sigma}_{x x}=\sigma_{x x}\left(\frac{a}{2}, \frac{b}{2}, \frac{h}{2}\right)\left(\frac{h^{2}}{a^{2} p}\right) \\
& \text { and } \bar{\sigma}_{y y}=\sigma_{y y}\left(\frac{a}{2}, \frac{b}{2}, \frac{h}{2}\right)\left(\frac{h^{2}}{a^{2} p}\right) .
\end{aligned}
$$

The generation of nodes in the two studied cases is shown in Figures 4 and 5.

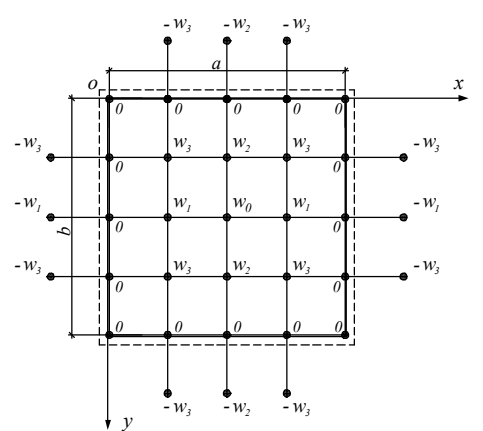

Fig. 4. Experimental plate with unknown nodes displacement (case $4 \mathrm{x} 4$ )

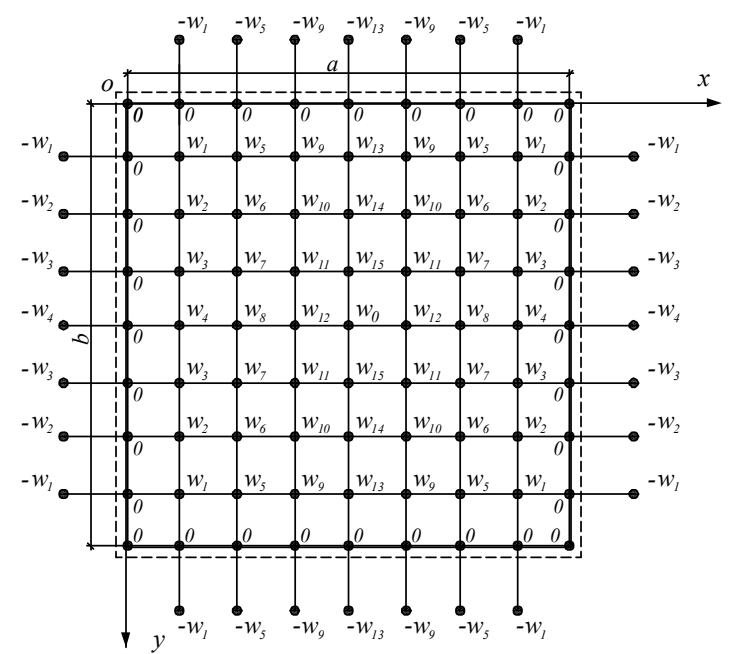

Fig. 5. Experimental plate with unknown nodes displacement (case 8x8)

The obtained results are compared in Table I. The small errors in Table 1 confirm the reliability of our program.

TABLE I. NON-DIMENSIONAL DEFLECTIONS AND STRESSES OF VALIDATION SAMPLE

\begin{tabular}{|c|c|c|c|}
\hline \multirow{2}{*}{ Models } & $\begin{array}{c}\text { Non-dimensional } \\
\text { deflections }\end{array}$ & \multicolumn{2}{|c|}{ Non-dimensional stresses } \\
\cline { 2 - 4 } & $\bar{w}$ & $\bar{\sigma}_{x x}$ & $\bar{\sigma}_{y y}$ \\
\hline Case study (4x4) & 0.0440 & 0.2813 & 0.2813 \\
\hline Case study (8x8) & 0.0443 & 0.2839 & 0.2839 \\
\hline$[\mathbf{1 8}]$ & 0.0444 & 0.2873 & 0.2873 \\
\hline FEM (Sap2000) & 0.0443 & 0.2839 & 0.2839 \\
\hline
\end{tabular}

The difference between the results does not exceed $0.5 \%$, while the case studies (8x8), [9] and FEM give equivalent results. This means that the research using FDM gives reliable and simple calculations.

\section{B. FDM Analysis of Rectangular Plates on Elastic Foundation Models}

The obtained results of non-dimensional deflections and stresses of the analysis of rectangular plates on rising Winkler and two-parameter elastic foundation models are shown in Tables II-III and Figures 6-7. We can see that the deflection of the plate changes when the elastic modulus increases. The rate of change of the non-dimensional deflection of the Winkler foundation model is about $5 \%$ of the two parameter 
foundation model. On the other hand, the variable dimension of the non-dimension variation of the two models is equivalent. The non-dimension stress of the two foundation models has also the same change.

TABLE II. NON-DIMENSIONAL DEFLECTIONS AND STRESSES ON RISING WINKLER FOUNDATION MODEL BY FDM

\begin{tabular}{|c|c|c|c|}
\hline \multirow{2}{*}{$k$} & $\begin{array}{c}\text { Non dimensional } \\
\text { deflections }\end{array}$ & \multicolumn{2}{c|}{ Non dimensional stresses } \\
\cline { 2 - 4 } & $\bar{w}$ & $\bar{\sigma}_{x x}$ & $\bar{\sigma}_{y y}$ \\
\hline $\mathbf{0}$ & 0.0443 & 0.2839 & 0.2839 \\
\hline $\mathbf{1 0 0 0}$ & 0.0431 & 0.2755 & 0.2755 \\
\hline $\mathbf{2 0 0 0}$ & 0.0419 & 0.2675 & 0.2675 \\
\hline $\mathbf{3 0 0 0}$ & 0.0408 & 0.2600 & 0.2600 \\
\hline $\mathbf{4 0 0 0}$ & 0.0398 & 0.2528 & 0.2528 \\
\hline $\mathbf{5 0 0 0}$ & 0.0388 & 0.2460 & 0.2460 \\
\hline
\end{tabular}

TABLE III. NON-DIMENSIONAL DEFLECTIONS AND STRESSES ON RISING TWO-PARAMETER FOUNDATION MODEL BY FDM

\begin{tabular}{|c|c|c|c|c|}
\hline \multirow{2}{*}{$k$} & \multirow{2}{*}{$k_{s}$} & $\begin{array}{c}\text { Non dimensional } \\
\text { deflections }\end{array}$ & \multicolumn{2}{|c|}{$\begin{array}{c}\text { Non dimensional } \\
\text { stresses }\end{array}$} \\
\cline { 3 - 5 } & & $\bar{w}$ & $\bar{\sigma}_{x x}$ & $\bar{\sigma}_{y y}$ \\
\hline $\mathbf{1 0 0 0}$ & $\mathbf{0}$ & 0.0431 & 0.2755 & 0.2755 \\
\hline $\mathbf{1 0 0 0}$ & $\mathbf{1 0 0 0}$ & 0.0409 & 0.2617 & 0.2617 \\
\hline $\mathbf{2 0 0 0}$ & $\mathbf{2 0 0 0}$ & 0.0398 & 0.2541 & 0.2541 \\
\hline $\mathbf{3 0 0 0}$ & $\mathbf{3 0 0 0}$ & 0.0387 & 0.2470 & 0.2470 \\
\hline $\mathbf{4 0 0 0}$ & $\mathbf{4 0 0 0}$ & 0.0378 & 0.2402 & 0.2402 \\
\hline $\mathbf{5 0 0 0}$ & $\mathbf{5 0 0 0}$ & 0.0368 & 0.2337 & 0.2337 \\
\hline
\end{tabular}

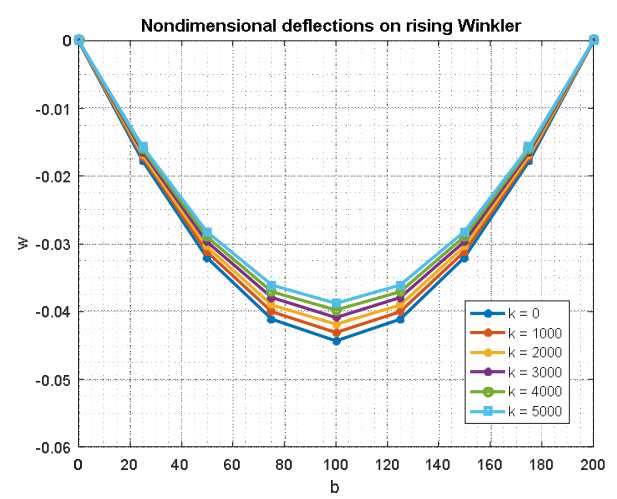

Fig. 6. Non-dimensional deflections on rising Winkler foundation

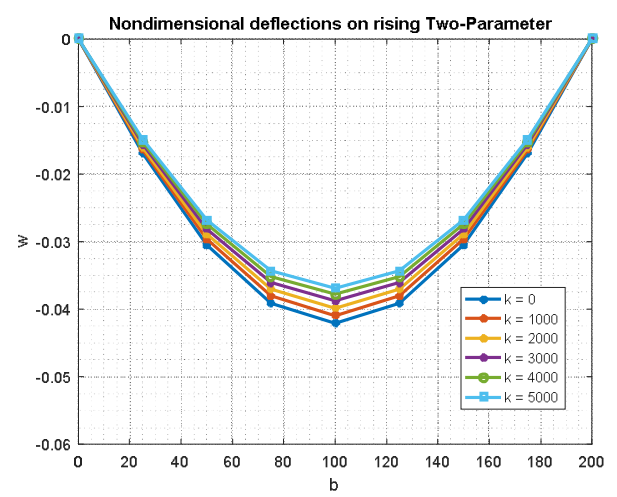

Fig. 7. Non-dimensional deflections on rising two-parameter foundation
C. Effect of a/b to Non-Dimensional Deflections and Stresses

The obtained results for rectangular plates on rising Winkler foundation with $a / b=\left[\begin{array}{lllll}1.0 & 1.5 & 2.0 & 2.5 & 3.0\end{array}\right]$, plate thickness $h=a / 100(\mathrm{~cm})$, differential mesh division $\Delta_{x}=a / 8(\mathrm{~cm})$ and $\Delta_{y}=b / 8(\mathrm{~cm})$, uniformly distributed load $p=-100 \mathrm{KN} / \mathrm{m}^{2}$, Young's modulus $E=2.1 \times 10^{5} \mathrm{MPa}$, Poisson's ratio $\mu=0.3$ and Winkler modulus $k=k_{s}=1000$, are shown in Table IV.

TABLE IV. NON-DIMENSIONAL DEFLECTIONS AND STRESSES

\begin{tabular}{|c|c|c|c|}
\hline \multirow{2}{*}{$\boldsymbol{a} / \boldsymbol{b}$} & \multicolumn{2}{|c|}{ Non-dimensional deflections } & \multicolumn{2}{c|}{ Non-dimensional stresses } \\
\cline { 2 - 4 } & $\bar{w}$ & $\bar{\sigma}_{x x}$ & $\bar{\sigma}_{y y}$ \\
\hline $\mathbf{1 . 0}$ & 0.0422 & 0.2696 & 0.2696 \\
\hline $\mathbf{1 . 5}$ & 0.0162 & 0.1313 & 0.1869 \\
\hline $\mathbf{2 . 0}$ & 0.0068 & 0.0663 & 0.1144 \\
\hline $\mathbf{2 . 5}$ & 0.0032 & 0.0351 & 0.0670 \\
\hline $\mathbf{3 . 0}$ & 0.0016 & 0.0194 & 0.0387 \\
\hline
\end{tabular}

(a)
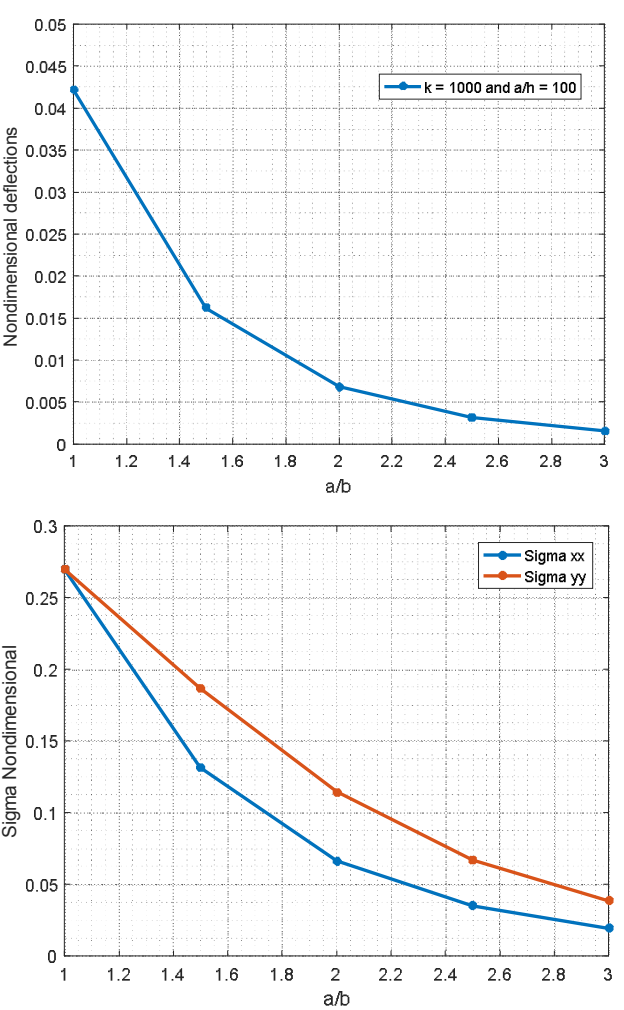

Fig. 8. Effect of the $a / b$ of variability on (a) non-dimensional deflections, and (b) non-dimensional stresses

In Table IV and Figure 8, we can see that the effect of $a / b$ to the non-dimensional deflections and stresses is significant. The variability of non-dimensional deflections is $[0.0422 \div$ $0.0016]$, of non-dimensional stresses $\bar{\sigma}_{x x}$ is $[0.2696 \div 0.0194]$ and has a larger fluctuation range $\bar{\sigma}_{y y}$ of $[0.2696 \div 0.0194]$. These obtained results confirm that the research is consistent with previous researches' results on the problem of plates on rising elastic foundation. 
D. Effect of the a/h to Non-Dimensional Deflections and Stresses

Consider rectangular plates on rising Winkler Foundation with input parameter $a / b=1$ and plate thickness $a / h=\left[\begin{array}{ll}50 & 100\end{array}\right.$ $150200250]$, differential mesh division $\Delta_{x}=\Delta_{y}=\Delta=a / 8 \mathrm{~cm}$, uniformly distributed load, $p=-100 \mathrm{KN} / \mathrm{m}^{2}$, Young' modulus $E=2.1 \times 10^{5} \mathrm{MPa}$, Poisson's ratio of the plate material $\mu=0.3$ and Winkler modulus $k=k_{s}=1000$. The obtained results are shown in Table V and Figure 9.

TABLE V. NON-DIMENSIONAL DEFLECTIONS AND STRESSES

\begin{tabular}{|c|c|c|c|}
\hline \multirow{2}{*}{$\mathbf{a} / \mathbf{h}$} & Non dimensional deflections & \multicolumn{2}{|c|}{ Non dimensional stresses } \\
\cline { 2 - 4 } & $\bar{w}$ & $\bar{\sigma}_{x x}$ & $\bar{\sigma}_{y y}$ \\
\hline $\mathbf{5 0}$ & 0.0441 & 0.2828 & 0.2828 \\
\hline $\mathbf{1 0 0}$ & 0.0431 & 0.2755 & 0.2755 \\
\hline $\mathbf{1 5 0}$ & 0.0404 & 0.2573 & 0.2573 \\
\hline $\mathbf{2 0 0}$ & 0.0361 & 0.2274 & 0.2274 \\
\hline $\mathbf{2 5 0}$ & 0.0307 & 0.1899 & 0.1899 \\
\hline
\end{tabular}

(a)

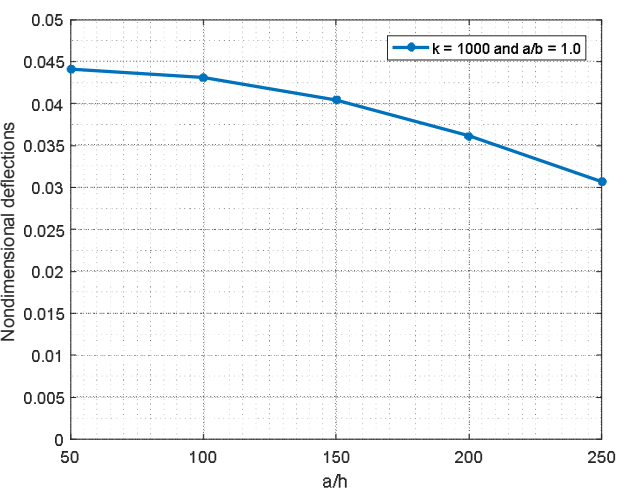

(b)

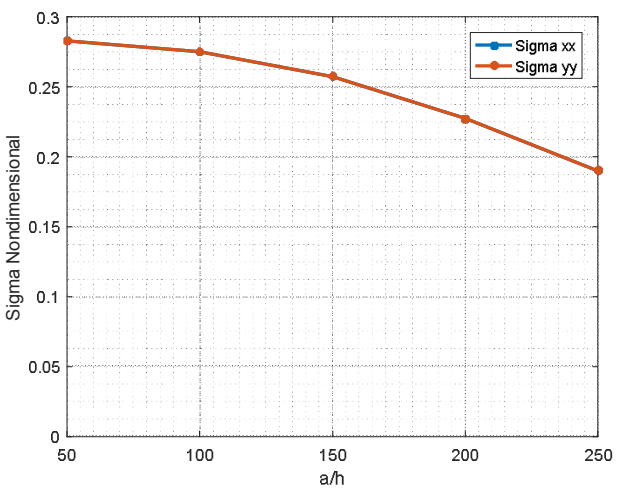

Fig. 9. Effect of the $a / h$ variability on (a) non-dimensional deflections, and (b) non-dimensional stresses

In Table $\mathrm{V}$ and Figure 9 we can see that the effect of $a / h$ to non-dimensional deflections and stresses is influential but not great. The variability of non-dimensional deflections is [0.0441 $\div 0.0307]$ and of non-dimensional stresses $\bar{\sigma}_{x x}$ and $\bar{\sigma}_{y y}$ is [0.2755 $\div 0.1899]$.

\section{CONCLUSION}

This paper studied the analysis of rectangular plates on resting Winkler and two-parameter elastic foundation models by using the Finite Difference Method. Authors utilized classical plate theory, Winkler and two-parameter elastic foundations, and FDM. Parametric tests were performed to study the effects of input parameters on the non-dimensional deflections and stresses. The obtained results showed the validity of this approach.

\section{REFERENCES}

[1] C. B. Dolicanin, V. B. Nikolic, D. C. Dolicanin, "Application of finite difference method to study of the phenomenon in the theory of thin plates", Scientific Publications of the State University of Novi Pazar, Vol. 2, No. 1, pp. 29-43, 2010

[2] A. Ghods, M. Mir, "Analysis of rectangular thin plates by using finite difference method", Journal of Novel Applied Sciences, Vol. 3, No. 3, pp. 260-267, 2014

[3] Roknuzzaman, B. Hossain, R. Haque, T. U. Ahmed, "Analysis of rectangular plate with opening by finite difference method", American Journal of Civil Engineering and Architecture, Vol. 3, No. 5, pp. 165173,2015

[4] S. A. Hemzah, M. A. Jaber, "Sector steel plate analysis using finite difference method", Journal of the University of Kerbala, Vol. 15, No. 3, pp. 79-93, 2017

[5] B. O. Mama, C. C. Ike, H. N. Onah, C. U. Nwoji, "Analysis of rectangular Kirchhoff plate on winkler foundationusing finite fourier sine transform method", IOSR Journal of Mathematics, Vol. 13, No. 4, pp. 58-66, 2017

[6] E. S. Melerski, "Simple computer analysis of circular rafts under various axisymmetric loading and elastic foundation conditions", Proceedings of the Institute of Civil Engineers, Vol. 89, No. 3, pp. 407-431, 1990

[7] C. V. Vallabhan, Y. C. Das, "Analysis of circular tank foundations", Journal of Engineering Mechanics,Vol. 117, No. 4, pp. 789-797, 1991

[8] I. M. Smith, "A finite element approach to elastic soil-structure interaction”, Canadian Geotechnical Journal, Vol. 7, No. 2, pp. 95-105, 1970

[9] L. Auersch, "Dynamic plate-soil interaction-finite and infinite, flexible and rigid plates on homogeneous, layered or Winkler soil", Soil Dynamics and Earthquake Engineering, Vol. 15, No. 1, pp. 51-59, 1996

[10] L. Sadecka, "Finite/infinite element analysis of thick plate on a layered foundation", Computers and Structures, Vol. 76, No. 5, pp. 603-610, 2000

[11] S. P. Timosenko, J. N. Dudier, Theory of Elasticity, Mcgraw Hill Education, 1962

[12] J. C. Ezeh, O. M. Ibearugbulem, C. I. Onyechere, "Pure bending analysis of thin rectangular flat plates using ordinary finite difference method", International Journal of Emerging Technology and Advanced Engineering, Vol. 3, No. 3, pp. 20-23, 2013

[13] J. S. Horvath, Soil-Structure Interaction Research Project, Manhattan College, 2011

[14] E. Winkler, Die Lehre Von Elastizitat und festigkeit, Dominicius, 1867

[15] P. L. Pasternak, "On a new method of analysis of an elastic foundation by means of two foundation constants", Gosudarstvennoe Izdatelstvo Literaturi po Stroitelstvu I Arkhitekture, Moscow, 1954

[16] M. Hetenyi, Beams on Elastic Foundation, The University of Michigan Press, 1946

[17] S. Timoshenko, S. Woinowsky-Krieger, Theory of Plates and Shells, McGraw-Hill, 1959

[18] J. N. Reddy, Theory and Analysis of Elastic Plates and Shells, CRC Press, 2006 